\title{
Frequency of Periapical Lesions Following Endodontic Treatment of Teeth
}

\author{
Dimitar L. Gospodinov, Petia F. Pechalova* \\ Department of Oral surgery, Faculty of dental medicine, Medical University, Plovdiv, Bulgaria \\ *Corresponding Author: Petia F. Pechalova, Department of Oral surgery, Faculty of dental medicine, \\ Medical University, Plovdiv, Bulgaria. Email: pechalova@abv.bg
}

\begin{abstract}
Summary: Apical lesions following endodontic treatment are an important criterion for assessment of the success.

The purpose of this study is to determine the frequency of periapicallesions following endodontic treatment of teeth by $x$-rays and their interconnection to the level of root canal filling.

Material and Methodology: One hundred and twenty (120) dental x-rays of 120 teeth following endodontic treatment were examined. Teeth were divided into maxillary and mandibular teeth; single rooted and multirooted teeth. Four groups were differentiated according to the level of root filling, measured from cavum to apex: Group one- up to $25 \%$ of the root canal length, Group two - up to 50\%; Group three - up to $75 \%$; Group four - over $75 \%$ of the root canal length filled. Dimensions of apical lesions were determined by measurement of the vertical and horizontal diameter.
\end{abstract}

Results: By the examination of 120 teeth, apical lesions were observed in 33 of them. Root canals filled to at least $50 \%$ of the root length were $92 \%$ (110 teeth), those with root filling of less than $50 \%$ of the root length were $8 \%$ (10 teeth). In the largest group - with canal filling of up to $75 \%$ there was the greatest number of apical lesions 28, 57\%. With the degree of filling of more than 75\%the number of detected apical lesions was $17,02 \%$.

Conclusion: Filling of the root canal up to the x-ray apex leads to smaller number of apical changes.

Keywords: Endodontic treatment, periapical lesion, roentgenography, x-ray

\section{INTRODUCTION}

Apical lesions following endodontic treatment are an important criterion for assessment of its efficiency. Properly conducted endodontic treatment may be a guarantee for the lack of periapical changes. Periapical lesions frequently lead to subjective complains, a reason for impaired stability of the tooth, and following extraction as a result. Information about the periapical space, tooth roots and their canals may be achieved by $\mathrm{x}$-ray examinations.

The most easily accessible and applicable in everyday practice of dentists is native $\mathrm{x}$-ray which has gained wide popularity. According to Khetarpalet all (1), human eye perceives illumination in a different way. Perception is different from light to grey and then to dark. To determine the result achieved by endodontic treatment of apical pathology and to register healing process in the lesion area $\mathrm{x}$-ray tracking is necessary during which the change of apical $\mathrm{x}$-ray air gap is assessed. (2) Initial detection of periapical chronic inflammations may be done by the subjective complains of the patient in a prolonged period, clinically by palpation or by percussion. Asymptomatic periodontitis exist which may not be diagnosed by clinical tests. Authors consider the conventional intraoral radiography to be a standard in $\mathrm{x}$-ray diagnostics. Mazumdar et all (3)compare three types of imaging examinations and define the indications for application of dental radiography with endodontics which include apical pathology, pulp disclosure and sinus tract; monitoring of the course of endodontic treatment, pathology of oral soft and hard tissue, included tumors, crown-root pathology especially odontoclastic resorptive lesions, crown and root fractures; periodontal diseases with access to bone levels, types of bone loss, combined periodontal-endodontic lesions. 
In clinical practice, along side with the conventional segment radiography, ortho pantomography and computed tomography and its subsection cone-beam computer tomography (CBCT) also play a role. CBCT has many advantages to the conventional radiography and may be used to diagnose periapical pathology, measurement of internal and external resorptive lesions, identification of perforations, fractures and traumas as well as for pre-operative planning of treatment.

The purpose of this study is to determine by $\mathrm{x}$ rays the frequency of periapical lesions following endodontic treatment and their relation to the level of root filling.

\section{MATERIALS AND METHODOLOGY}

This study covers 120 conventional $\mathrm{x}$-rays of patients who underwent endodontic treatment of teeth atleast 12 months ago and have not had subjective complains throughout that period. Xrays were taken by Planmeca ProXapparatus, which corresponds to the requirements of Regulation 93/42/EEC (exposure values- 60kv, $7 \mathrm{~mA}$, time 0.080). The total number of visualized teeth was 285 . Of the visualized teeth, $120(42 \%)$ had prior endodontic treatment and were subject of this study. All teeth were divided into two groups according to the number of their roots and according to their allocation in the jaws. Subject of examination was the level of root filling along the canal -from cavum to apex by comparing the measured length of root canal and the length of root filling. For each tooth the $x$-ray image of the root canal was measured from cavum to apex and after that the length of root filling was measured in millimeters and the relevant calculations were performed. According to their root filling level, four groups were formed: Group one - up to $25 \%$ of the root canal length, Group two - up to $50 \%$ of the root canal length, Group three - up to $75 \%$ of the root canal length, Group four over $75 \%$ of the root canal length. The horizontal and the vertical diameter of each lesion were measured in millimeters.

\section{Results}

Out of the total of 120 teeth included in the study, 86 had one root (72\%); 34 had multiple roots $28 \%$. Ninety one of the studied teeth were maxillary $(76 \%)$ and 28 teeth $(24 \%)$ were of the mandible.

Canal filling agent was found in the root canals of all teeth included in the study.
The greatest number of teeth fell into the third group -63teeth $(52,5 \%)$. The group with completely obturated root canals (group IV) accounted to 47 teeth $(39,17 \%)$. Only 3teeth $(2$, $5 \%)$ fell in to group one and 7 teeth $(5,83 \%)$ into group two (fig. 1).

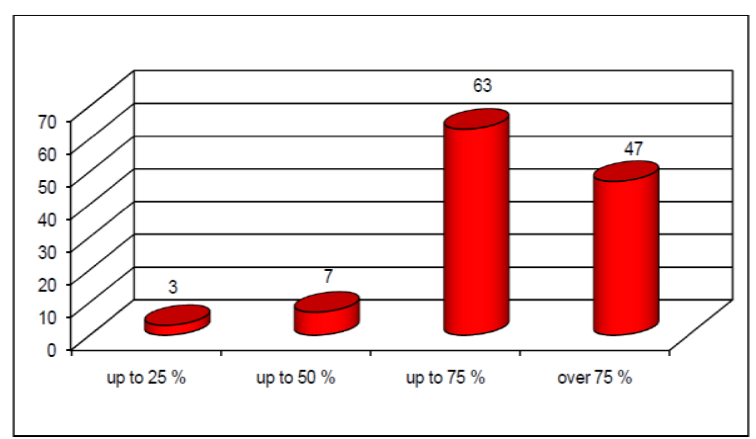

Figure1. Distribution of teeth according to the level of endodontic filling

Examination of x-rays determined $33(27,5 \%)$ apical lesions out of the total of one hundred and twenty studied teeth (fig.2).

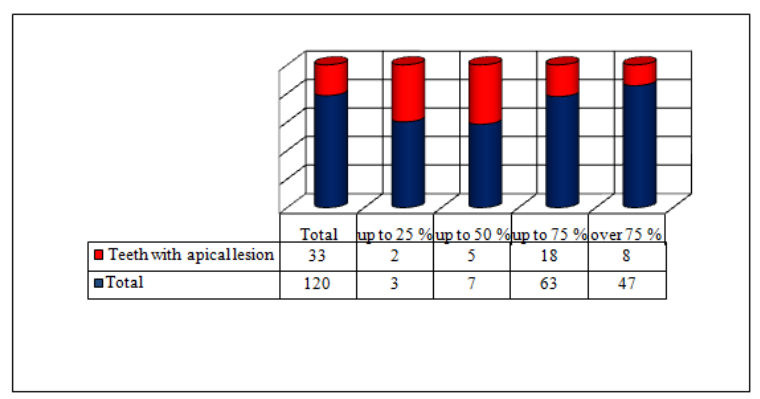

Figure2. Ratio between all studied teeth and the teeth with periapical lesions according to the determined level of root canal filling

Results of the exploration of size of lesions may be found on figure 3 . The smallest apical lesion was with horizontal diameter of $0,20 \mathrm{~mm}$ and vertical diameter of $0,10 \mathrm{~mm}$. The biggest one horizontal diameter $6,0 \mathrm{~mm}$ and vertical diameter $-5,00 \mathrm{~mm}$. Average size of the examined thirty-three lesions was $1,38 \mathrm{~mm}$ horizontal and $1,34 \mathrm{~mm}$ vertical diameter.

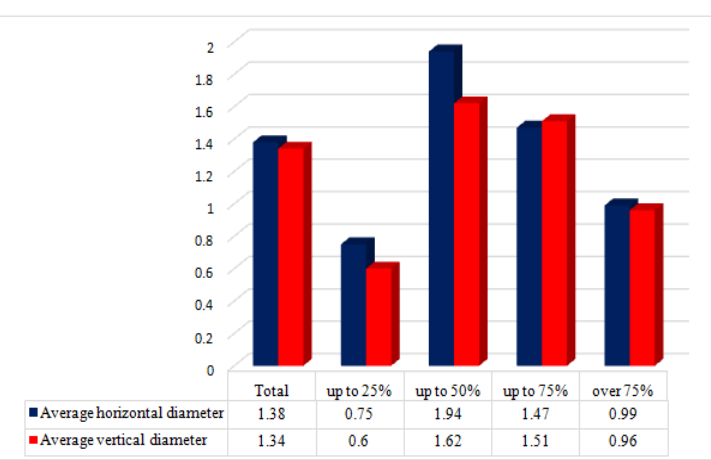

Figure3. Distribution of average diameters of lesions according to the level of root canal filling. 
In the first group the smallest lesion was with horizontal diameter of $0,5 \mathrm{~mm}$ and vertical diameter of $0,2 \mathrm{~mm}$, the biggest one - horizontal diameter $1 \mathrm{~mm}$ and vertical diameter $-1 \mathrm{~mm}$. Average size of the examined lesions was 0,75 $\mathrm{mm}$ horizontal and $0,6 \mathrm{~mm}$ vertical diameter.

In the second group the smallest lesion was with horizontal diameter of $0,2 \mathrm{~mm}$ and vertical diameter of $0,1 \mathrm{~mm}$, the biggest one - horizontal diameter $6 \mathrm{~mm}$ and vertical diameter $-5 \mathrm{~mm}$. Average size of the examined lesions was $1.94 \mathrm{~mm}$ horizontal and $1,26 \mathrm{~mm}$ vertical diameter.

In the third group the smallest lesion was with horizontal diameter of $0,2 \mathrm{~mm}$ and vertical diameter of $0,2 \mathrm{~mm}$, the biggest one - horizontal diameter $4 \mathrm{~mm}$ and vertical diameter- $4.5 \mathrm{~mm}$. Average size of the examined lesions was $1.47 \mathrm{~mm}$ horizontal and $1.51 \mathrm{~mm}$ vertical diameter.

In the fourth group the smallest apical lesion was with horizontal diameter of $0,5 \mathrm{~mm}$ and vertical diameter of $0,3 \mathrm{~mm}$, the biggest one horizontal diameter $3.5 \mathrm{~mm}$ and vertical diameter $-3.5 \mathrm{~mm}$. Average size of the examined lesions was $0,99 \mathrm{~mm}$ horizontal and $0,96 \mathrm{~mm}$ vertical diameter.

With all teeth the average horizontal diameter was bigger than the average vertical diameter. In the groups I, II and IV results were identical. In group III, on the contrary the average vertical diameter proved to be bigger than the average horizontal diameter.

\section{DisCUSSION}

In the dental practice application of conventional radiography and orthopantomography is wide spread. Prevailing opinion is that intra oralx-rays are more informative in respect to periapical lesions if compared to orthopantomography. Molander et all (4) studied 200 panoramic and 200 intra oral $\mathrm{x}$-rays of 400 patients for periapical pathology and found out that conventional intra oral $\mathrm{x}$-rays register more osteolyticlesions (63\%) compared to the lesions determined by orthopantomography (55\%).

Peciuliene et all (5)performed clinical and radiological monitoring of the dental status of 83 patients for a period of one year. They established that out of 2186 teeth, 283 undergo endodontic treatment; 122 teeth $(43,1 \%)$ of those developed $\mathrm{x}$-ray data for periapical lesions. Only $28,6 \%$ of the prior endodontically treated teeth met the criteria for acceptable filling, according to the European Association of Endodontists - radiologically filling should be distanced from 0 to $3 \mathrm{~mm}$ from the tooth apex, whilst 58,3\%(165 teeth) were with inadequate filling. Filled teeth without indications for apical periodontitis were $21 \%$ (25 teeth). The same study examined the occurrence of apical lesions with teeth with old endodontic treatment. Authors reported that out of 183 teeth with endodontic treatment provided long ago, 99 had apical lesions. In this study apical lesions prevailed with insufficient canal's filling and bad adaptation to canal walls and are represented in $43 \%$ of the teeth with canal fillings.

Jersa et all (6) examined orthopantomographies in Latvia and established the frequency of periapical lesions of teeth following endodontic treatment of $72 \%$. Data from Lithuania are similar- $70 \%$ (7) and Belorusia - 85\% (8). The frequency of periapical lesions of teeth following endodontic treatment determined by our study is $27,5 \%$ and it is closer in value to the data of Marques et all (9)for Portugal - 27\% and of Skudutyte-Rysstad et all (10) for Norway $16 \%$.

Our study established that occurrence of apical lesions is in direct correlation with the quality of endodontic treatment. This conclusion was confirmed by other authors as well. Petersson (11) found out that teeth with partially obturated root canals will much more frequently develop apical period on tit is if compared to teeth with completely obturated root canals. Jersaet all (6)found out that in teeth with partially obturated root canals the frequency of apical lesions is $35 \%$, while in teeth with completely obturated root canals, apical lesions may be detected in $15 \%$ of them. This relation has been documented by other scientists as well. $(\mathbf{1 2}, \mathbf{1 3})$

\section{Conclusion}

Compromised endodontic treatment relates to higher risk of development of apical lesion. Intra oral x-rays are the optimal tools to monitor the apical zone following endodontic treatment. 


\section{REFERENCES}

[1] Khetarpal A, Chaudhary S, Sahai S, Talwar S, Verma M. Radiological assessment of periapical healing using the cone beam computed tomography periapical index: case report. IOSR Journal of Dental and Medical Sciences (e-ISSN: 2279-0853) 2013; 9(5):4651.

[2] Peters CI, Peters OA.Cone beam computed tomography and other imaging techniques in the determination of periapical healing. Endodontic topics 2012; 26(1): 57-75.

[3] Mazumdar P, Das UK, Bhattacharyya S. Comparative role of conventional radiography, radiovisiography and cone beam tomography on 'Dimension determination' of persistent periapical radiolucency in relation to treatment planning. International Journal of Innovation and Applied Studies 2015(ISSN 2028-9324); 10(1): 1-7.

[4] Molander B, Ahlqwist M, Gröndahl HG, Hollender L. Comparison of panoramic and intraoral radiography for the diagnosis of caries and periapical pathology. Dentomaxillofac Radiol. 1993; 22(1):28-32.

[5] Peciuliene V, Rimkuviene J, Maneliene R, IvanauskaiteD.Apical periodontitis in root filled teeth associated with the quality of root fillings. Baltic Dental and Maxillofacial Journal, 8:1226, 2006.

[6] Jersa I, Kundzina R. Periapical status and quality of root fi llings in a selected adult Riga population. Stomatologija, Baltic Dental and Maxillofacial Journal 2013; 15: 73-7.

[7] Sidaravicius B, Aleksejuniene J, Eriksen HM. Endodontic treatment and prevalence of apical periodontitis in an adult population of Vilnius, Lithuania. Endod Dent Traumatol 1999;15:2105.

[8] Kabak Y, Abbott PV. Prevalence of apical periodontitis and the quality of endodontic treatment in an adult Belarusian population. Int Endod J 2005;38:238-45.

[9] Marques MD, Moreira B, Eriksen HM. Prevalence of apical periodontitis and results of endodontic treatment in an adult, Portuguese population. Int Endod J 1998;31:161-5.

[10] Skudutyte-Rysstad R, Eriksen HM. Endodontic status amongst 35-year-old Oslo citizens and changes over a 30-year period.Int Endod J 2006;39:637-42.

[11] Petersson K. Endodontic status of mandibular premolars and molars in an adult Swedish population. A longitudinal study 1974-1985. Endod Dent Traumatol 1993;9:13-8.

[12] Loftus JJ, Keating AP, McCartan BE. Periapical status and quality of endodontic treatment in an adult Irish population. Int Endod J 2005;38:81-6.

[13] Lupi-Pegurier L, Bertrand MF, Muller-Bolla M, Rocca JP, Bolla M. Periapical status, prevalence and quality of endodontic treatment in an adult French population. Int Endod $\mathbf{J}$ 2002;35:690-7.

Citation: Dimitar L. Gospodinov, Petia F. Pechalova. Frequency of Periapical Lesions Following Endodontic Treatment of Teeth. ARC Journal of Dental science. 2017; 2(2): 14-17. doi:dx.doi.org/10.20431/24560030.0202004 .

Copyright: (C) 2017 Authors. This is an open-access article distributed under the terms of the Creative Commons Attribution License, which permits unrestricted use, distribution, and reproduction in any medium, provided the original author and source are credited. 